\title{
New oral anticoagulants - will they be used with antiplatelet drugs in patients with atrial fibrillation after acute coronary syndrome?
}

\author{
Iwona Gorczyca-Michta, Beata Wożakowska-Kapłon \\ $1^{\text {st }}$ Clinic of Cardiology, Swietokrzyskie Centre of Cardiology, Faculty of Health Studies, Jan Kochanowski University, Kielce, Poland
}

Postep Kardiol Inter 2013; 9, 4 (34): 348-352 DOI: $10.5114 /$ pwki.2013.38864

\begin{abstract}
A bstract
Atrial fibrillation (AF) is the most frequent indication for oral anticoagulation. Dual antiplatelet treatment with aspirin and clopidogrel is an antithrombotic treatment recommended after acute coronary syndrome and/or coronary artery stenting. The evidence for optimal antiplatelet therapy for patients who underwent a long-term treatment based on oral anticoagulation is strong. A direct thrombin inhibitor, dabigatran, as well as direct factor $\mathrm{X}$ inhibitors, apixaban and rivaroxaban, are now being commonly used in the prevention of thromboembolic complications of AF. Given the consistent increase in bleeding and the less consistent reduction in ischaemic events, the overall profile of adding new oral anticoagulants to antiplatelet treatment after acute coronary syndrome is unknown.
\end{abstract}

Key words: atrial fibrillation, new oral anticoagulants.

\section{Use of the new oral anticoagulants in the prevention of thromboembolic complications of atrial fibrillation in the applicable guidelines}

The prevention of thromboembolic complications is a priority action in patients with atrial fibrillation (AF). It is estimated that oral anticoagulants are recommended for $70-80 \%$ of patients with AF [1]. At the same time, AF co-exists with ischaemic heart disease in $20-30 \%$ of patients, which implies that there is a certain group of patients treated with anticoagulants who will also require antiplatelet therapy after acute coronary syndromes and/ or coronary interventions [2]. The direct thrombin inhibitor dabigatran, as well as the direct factor $X$ inhibitors apixaban and rivaroxaban, are now being commonly used in the prevention of thromboembolic complications of AF.

The guidelines of the European Society of Cardiology (ESC) from 2012 are based on the growing evidence of efficacy of the new oral anticoagulants in preventing thromboembolic complications of AF [3]. Anticoagulant treatment in the prevention of thromboembolic complications is recommended for all patients with AF, with the exception of those with a really low risk (un- der the age of 65 years with isolated AF) and those with contraindications. Patients whose risk of thromboembolic complications amounts to 2 points or more in the CHA2DS2VASC score should receive a vitamin $\mathrm{K}$ antagonist or a new oral anticoagulant (class I recommendations, level of evidence A). Having considered the risk of bleeding and the patient's preferences, the application of a vitamin $\mathrm{K}$ antagonist or a new anticoagulant (class lla recommendations, level of evidence $A$ ) should be taken into account in the case of patients whose score was CHA2DS2VASC = 1 point. In both cases the new oral anticoagulants are preferred [3]. The new oral anticoagulants have the highest class of recommendations among patients with indications for anticoagulant therapy if treatment with vitamin $\mathrm{K}$ antagonists is not possible due to the following factors: difficulties in maintaining the therapeutic international normalized ratio (INR), adverse effects of treatment based on vitamin $\mathrm{K}$ antagonists, or the lack of possibility of monitoring INR (class I recommendations, level of evidence B) [3]. As a consequence of considerable evidence of safety and efficacy of dabigatran, rivaroxaban and apixaban, the new oral anticoagulants are being commonly used in the prevention of thromboembolic complications.

\section{Corresponding author:}

Iwona Gorczyca-Michta MD, PhD, $1^{\text {st }}$ Clinic of Cardiology, Świetokrzyskie Centre of Cardiology, 45 Grunwaldzka St, 25-637 Kielce, Poland, e-mail: iwona.gorczyca@interia.pl

Received: 27.08.2013, accepted: 10.10.2013. 


\section{Vitamin $\mathrm{K}$ antagonists administered in therapy combined with antiplatelet drugs}

The application of antiplatelet drugs in patients after acute coronary syndromes and/or coronary interventions has led to a significantly decreased death rate in this group [4]. It has been indicated that warfarin used in monotherapy or in therapy combined with acetylsalicylic acid (ASA) lowers the risk of secondary ischaemic attacks [5]. The meta-analysis of 9 studies conducted by Zhao et al. [6] to evaluate the efficacy of antithrombotic therapy in patients with indications for anticoagulant treatment after percutaneous coronary intervention (PCI), carried out on approximately 2000 patients, showed that triple anticoagulant therapy leads to better results in the prevention of cardiovascular events than double antiplatelet therapy (death due to cardiological causes, heart attack, thrombosis in a stent and a second revascularization; $\mathrm{OR}=0.60,95 \% \mathrm{Cl}: 0.42-0.86 ; p=$ 0.005). Triple antithrombotic therapy decreased the death rate significantly $(\mathrm{OR}=0.38,95 \% \mathrm{Cl}$ : 0.39-0.90; $p=0.01$ ); however, major bleeding occurred more often than in the case of double antiplatelet therapy (OR = 2.12, $95 \% \mathrm{Cl}: 1.05-4.29 ; p=0.04)$. The findings of this meta-analysis confirmed that, in comparison with double antiplatelet therapy, triple anticoagulant therapy increases the risk of haemorrhagic complications after stent implantation in patients with indications for longterm anticoagulant treatment. Nearly all major bleeding events occurred in the first 6 months of the administration of the anticoagulant in combination with antiplatelet drugs and were most often related to the excessive INR. In the light of these findings it can be concluded that a therapy combined with antiplatelet drugs and vitamin $\mathrm{K}$ antagonists improves prognosis in patients with AF after $\mathrm{PCl}$. However, its safety is dependent on the frequent monitoring of INR and the application of anticoagulant treatment to obtain the INR of 2.0-2.5. A documentation of the Working Group on Thrombosis (European Society of Cardiology - ESC), approved by the European Heart Rhythm Association (EHRA) and the European Association of Percutaneous Cardiovascular Interventions (EAPCI), illustrates the principles of anticoagulant and antiplatelet therapies in patients with AF after planned $\mathrm{PCl}$ or acute coronary syndrome [7]. A decision on the duration of antiplatelet and anticoagulant combination therapies needs to be made upon a scrupulous assessment of thromboembolism and haemorrhagic risks. In all patients with AF after acute coronary syndrome, regardless of the risk factors and clinical situation, the therapy must be initiated by applying two antiplatelet drugs and a vitamin $\mathrm{K}$ antagonist. The duration of the triple therapy depends on the clinical situation, bleeding risk and the type of stent, whereas the INR should amount to 2.0-2.5. In the period of 12 months all patients who recovered from acute cor- onary syndrome and were subjected to planned $\mathrm{PCl}$ as well as the implantation of stents coated with antimitotic substances should receive a vitamin $\mathrm{K}$ antagonist and one of the antiplatelet drugs. Discontinuation of therapy based on clopidogrel or acetylsalicylic acid should result from the doctor's decision. After 12 months of treatment it is recommended to stop taking the antiplatelet drug and continue therapy based on a vitamin $\mathrm{K}$ antagonist to obtain the INR of 2.0-3.0 [7].

\section{New oral anticoagulants administered in therapy combined with antiplatelet drugs in the light of clinical studies}

The first new oral anticoagulant whose safety and efficacy were assessed in a therapy combined with an antiplatelet drug was ximelagatran. The ESTEEM study was carried out on 1900 subjects after acute coronary syndrome with AF. The administration of ximelagatran and the antiplatelet drug decreased the risk of a second heart attack in the study group [8]. However, due to its hepatic toxicity, ximelagatran has not been registered for use in the prevention of thromboembolic complications of AF.

The REEDEM study was conducted on 1861 patients after acute coronary syndrome. Sixty percent of these patients recovered from ST elevation myocardial infarction (STEMI) and 40\% from non-ST elevation myocardial infarction (NSTEMI) [9]. A double antiplatelet therapy was applied to $99 \%$ of the examined patients. Major bleeding events according to the ISTH scoring system (resulting in the patient's death, in a critical condition, or leading to a decrease in the levels of haemoglobin by at least $2 \mathrm{~g} / \mathrm{dl}$ or transfusions of a minimum of 2 units of packed red blood cells) or minor but clinically significant complications occurred during the 6-month follow-up of $7.9 \%$ of patients who were treated with antiplatelet drugs and dabigatran at a dose of $2 \times 110 \mathrm{mg}$ and $7.8 \%$ of patients receiving antiplatelet drugs and dabigatran at a dose of $2 \times 150 \mathrm{mg}$. The frequency of haemorrhagic complications in a group of patients who received antiplatelet drugs and placebo amounted to $2.8 \%$. The outcome event being a composite of cardiovascular death, nonfatal $\mathrm{MI}$ and non-haemorrhagic stroke was observed in 3.5\%, 3\%, 4.9\% and $4.6 \%$ of patients treated with dabigatran at a dose of $2 \times 150 \mathrm{mg}, 2 \times 110 \mathrm{mg}, 2 \times 75 \mathrm{mg}$ and $2 \times 50 \mathrm{mg}$ respectively. The frequency of a composite outcome event among patients treated with placebo was 3.8\% [9].

The safety and efficacy of apixaban in the combination with antiplatelet drugs were assessed in the APPRAISE study, which included 1715 subjects [10]. It was concluded that a higher dose of apixaban led to an increased frequency of haemorrhagic complications, which most often included the following conditions: haematomas, gingival and gastrointestinal bleeding, and haematuria. The frequency of cardiovascular death, MI and ischaemic stroke was higher among patients receiving apixaban 
than those treated with placebo. However, this difference was not statistically significant. The most significant benefits from the application of apixaban were observed in patients receiving one antiplatelet drug and in patients who were not subjected to revascularization [10]. The APPRAISE-2 study, which was carried out on 7392 patients randomized approx. on the sixth day of acute coronary syndrome to receive apixaban at a dose of $2 \times 5 \mathrm{mg}(2 \times$ $2.5 \mathrm{mg}$ in the case of impaired renal function) or placebo, also provided evidence of a significant increase of the risk of haemorrhagic complications in a group of patients treated with apixaban in relation to those who received placebo (1.3\% vs. $0.5 \%, p=0.001)$ [11]. In the APPRAISE-2 study, as well as in the studies based on rivaroxaban, the thrombolysis in myocardial infarction (TIMI) definition of haemorrhagic complications was applied. According to this definition, intracranial bleeding and clinical bleeding significantly related to a haemoglobin drop by at least $5 \mathrm{~g} / \mathrm{dl}$ or haematocrit drop by at least $15 \%$ were considered as major bleeding. The incidence of the primary outcome event whose sub-components were cardiovascular death, $\mathrm{MI}$ and ischaemic stroke amounted to $13.2 / 100$ patient years in the case of patients treated with apixaban and 14/100 patient years in the case of those receiving placebo $(\mathrm{HR}=0.95,95 \% \mathrm{Cl}$ : 0.8-1.11). The RUBY-1 study evaluated the safety and efficacy of darexaban in the prevention of ischaemic episodes in patients after acute coronary syndromes. Adding darexaban in different daily doses (from $10 \mathrm{mg}$ to $60 \mathrm{mg}$ ) to a double antiplatelet therapy resulted in a 2-4-fold increase in the risk of haemorrhagic complications in comparison with the placebo group [12].

The first study in which rivaroxaban was administered in a combination with antiplatelet drugs in patients after acute coronary syndrome was the ATLAS ACS TIMI 46 study. It was carried out on 3491 patients who were randomized to receive 5-20 mg of rivaroxaban daily. Unlike placebo, the administration of the lowest doses of rivaroxaban led to the safe and effective reduction of the primary composite outcome event: death, $\mathrm{Ml}$ or stroke. At the same time an increased incidence of haemorrhagic complications, which was proportional to the rivaroxaban dose, was reported [13]. The study of the third phase, ATLAS ACS 2 TIMI 51, was designe $d$ on the basis of the obtained results. It was conducted on 15526 patients after acute coronary syndrome who had at least one additional risk factor: age > 55 years, diabetes or MI. The patients were randomized no later than on the seventh day of acute coronary syndrome to a group receiving rivaroxaban at a dose of $2 \times 2.5 \mathrm{mg}, 2 \times 5 \mathrm{mg}$, or placebo. In the examined group $93 \%$ of patients received a double antiplatelet therapy. The administration of a dose of $2 \times 2.5 \mathrm{mg}$, as opposed to placebo, resulted in a decrease in the incidence of the primary outcome event composed of cardiovascular death, $\mathrm{MI}$ and stroke by $15 \%$, whereas the cardiovascular mortality dropped by $38 \%$ and the number of deaths from any cause was reduced by $36 \%$. Rivaroxaban, in contrast to placebo, decreased the incidence of thrombosis in a stent, which occurred in $2.3 \%$ of patients treated with rivaroxaban and $2.9 \%$ of patients receiving placebo ( $\mathrm{HR}=0.69 ; 95 \% \mathrm{Cl}: 0.51-0.93 ; p=0.02)$ [14]. In terms of the therapy safety major bleeding events not related to surgery were observed more often in patients who were treated with rivaroxaban than in those who received placebo $(2.1 \%$ vs. $0.6 \% ; p<0.001)$. The same applied to minor bleeding ( $1.3 \%$ vs. $0.5 \% ; p=0.003$ ), bleeding which required medical intervention $(14.5 \%$ vs. $7.5 \% ; p<0.001)$, and intracranial bleeding ( $0.6 \%$ vs. $0.2 \% ; p=0.009)$. Nevertheless, an increased risk of fatal bleeding was not reported ( $0.3 \%$ vs. $0.2 \% ; p=0.66)$. In the group of patients treated with rivaroxaban the risk of bleeding was lower when a daily dose of $2 \times 2.5 \mathrm{mg}$ was administered [14].

However, the findings of the ATLAS ACS 2 TIMI 51 study have not answered whether acetylsalicylic acid, clopidogrel and rivaroxaban are going to be administered to patients with AF who recovered from acute coronary syndrome. It was indicated that in triple therapy the safest and most effective dose was $2.5 \mathrm{mg}$ twice daily, whereas in the prevention of thromboembolic complications of $\mathrm{AF}$ the registered dose of rivaroxaban is $20 \mathrm{mg} /$ day $(15 \mathrm{mg}$ for patients with impaired renal function or high risk of haemorrhagic complications) [15]. Table 1 contains a summary of the presented clinical studies.

\section{New oral anticoagulants administered in therapy combined with antiplatelet drugs in meta-analyses of clinical studies}

Komócsi et al. [16] conducted an analysis of prospective and randomized placebo-controlled studies which were published in the period from January 2000 to December 2011. The researchers assessed the results of the Xa factor inhibitor or direct thrombin inhibitors in 31286 patients who received antiplatelet therapy after acute coronary syndrome. The administration of the new oral anticoagulants in patients receiving antiplatelet drugs after acute coronary syndrome led to a threefold increase of the risk of major haemorrhagic complications $(\mathrm{HR}=$ 3.03, $p<0.001)$. A moderate but significant reduction of thrombosis in a stent or a decrease in the total number of ischaemic events without increasing the overall death rate was reported. The authors of this meta-analysis indicated that the administration of the new oral anticoagulants did not bring better results than placebo in terms of the net clinical benefit $(H R=0.98, p=0.57)$ [16]. The meta-analysis of Oldgren et al. [15] included the following studies: ESTEEM [8], REEDEM [9], RUBY-1 [12], APPRAISE-1 [10], APPRAISE-2 [11], ATLAS ACS-TIMI 46 [13] and ATLAS ACS 2 TIMI 51 [14]. Death from any cause, myocardial in- 
Table 1. Clinical studies based on the new oral anticoagulants in combination with antiplatelet drugs

\begin{tabular}{|c|c|c|c|c|c|}
\hline Study & Examined drug & $\begin{array}{l}\text { Duration } \\
\text { [months] }\end{array}$ & $\begin{array}{l}\text { Number of } \\
\text { patients }\end{array}$ & $\begin{array}{l}\text { Average age } \\
\text { [years] }\end{array}$ & $\begin{array}{l}\text { Percentage of patients } \\
\text { receiving two } \\
\text { antiplatelet drugs [\%] }\end{array}$ \\
\hline ESTEEM [8] & $\begin{array}{c}\text { ximelagatran } 24,36,48 \text { or } 60 \mathrm{mg} \text { b.i.d., } \\
\text { or placebo }\end{array}$ & 6 & 1900 & 68 & 0 \\
\hline APPRAISE-1 [10] & $\begin{array}{c}\text { apixaban } 2.5 \text { mg b.i.d., } 10 \text { mg o.d. } \\
\text { or placebo }\end{array}$ & 6 & 1715 & 61 & 76 \\
\hline APPRAISE-2 [11] & apixaban $2.5 \mathrm{mg}$ or 5 b.i.d. or placebo & 8 & 7392 & 67 & 81 \\
\hline REDEEM [9] & $\begin{array}{c}\text { dabigatran } 50,75,100 \text { or } 150 \mathrm{mg} \text { b.i.d. } \\
\text { or placebo }\end{array}$ & 6 & 1878 & 62 & 98 \\
\hline $\begin{array}{l}\text { ATLAS } \\
\text { ACS-TIMI } 46 \text { [13] }\end{array}$ & $\begin{array}{l}\text { rivaroxaban } 5,10 \mathrm{mg} \text { o.d., } 5 \mathrm{mg} \text { b.i.d. } \\
\text { or placebo }\end{array}$ & 6 & 3462 & 57 & 75 \\
\hline $\begin{array}{l}\text { ATLAS } \\
\text { ACS2-TIMI } 51[14]\end{array}$ & rivaroxaban 2.5, 5 mg b.i.d. or placebo & 13 & 15526 & 62 & 93 \\
\hline RUBY-1 [12] & $\begin{array}{l}\text { darexaban } 5,15,30 \mathrm{mg} \text { b.i.d., } \\
\text { 10, } 30,60 \mathrm{mg} \text { o.d. or placebo }\end{array}$ & 6 & 1279 & 57 & 95 \\
\hline
\end{tabular}

b.i.d. - twice a day, o.d. - once a day

farction and stroke were considered as major adverse cardiac events (MACEs). $13.4 \%$ of patients from the examined group received one antiplatelet drug, whereas double antiplatelet therapy was applied to $86.6 \%$ of patients. On the one hand, the administration of a new oral anticoagulant in patients who received only ASA reduced the incidence of MACEs by $30 \%$ but on the other hand it increased the incidence of bleeding by $79 \%$. In a group of patients who were treated with two antiplatelet drugs the administration of a new oral anticoagulant reduced the risk of MACEs by $13 \%$, whereas the risk of bleeding increased by $134 \%$. The analysis was carried out on a subgroup of patients from the studies of the third phase (APPRAISE-2 and ATLAS ACS 2 TIMI 51), which indicated that the addition of apixaban or rivaroxaban to single or double antiplatelet therapy resulted in a $15 \%$ decrease in the incidence of MACEs. However, the risk of haemorrhagic complications increased threefold.

\section{New oral anticoagulants in therapy combined with antiplatelet drugs - the opinions of specialists}

In 2012 the ESC Working Group on Thrombosis published a document on the administration of the new oral anticoagulants to patients with AF after acute coronary syndromes. The document was based on the outcome of studies published up to 2012 in which the new oral anticoagulants and antiplatelet drugs were used. The specialists underlined numerous advantages of the new oral anticoagulants in comparison with vitamin $\mathrm{K}$ antagonists in patients with AF. According to the authors the new oral anticoagulants will be used to treat patients with AF after acute coronary syndromes. However, further studies are necessary to establish the recommended doses of the new oral anticoagulants which will prove both effec- tive in the prevention of thromboembolic complications and safe in terms of therapy combined with antiplatelet drugs [17]. The Polish specialists point to the significance of an individual approach to clinical situations with the consideration of the risk of thromboembolic and haemorrhagic complications, and underscore the lack of studies conducted on patients with AF after acute coronary syndrome, which would allow for lawful administration of the new anticoagulants in combination with antiplatelet drugs in this group of patients [18].

\section{Prospects for anticoagulant and antiplatelet treatment of patients with atrial fibrillation after acute coronary syndromes in the near future}

Three new anticoagulant drugs have been registered in the prevention of thromboembolic complications of AF: apixaban, dabigatran and rivaroxaban. They are being commonly used due to their efficacy, which is comparable to that of the vitamin $\mathrm{K}$ antagonists, a higher safety profile and a simple administration schedule. The findings of the studies which have been carried out so far do not allow for the formulation of indications referring to the administration of the new oral anticoagulants in patients with AF after acute coronary syndrome. None of the conducted studies resulted in determining a dose of the new oral anticoagulants which would be safe in combination with antiplatelet drugs in the aspect of haemorrhagic complications and effective in the prevention of thromboembolic complications [19]. The situation is worsening due to the common practice of replacing clopidogrel with prasugrel and ticagrelor in patients after acute coronary syndromes. Prasugrel and ticagrelor are indicated for patients after STEMI [20] and NSTEMI [21] and, according to the recommendations, clopido- 
grel should be a part of the alternative treatment for this group. These drugs are safer and more effective than clopidogrel but their application is limited due to the high costs of therapy. Currently no results of studies evaluating the combination of the new oral anticoagulants with prasugrel or ticagrelor are available. It appears that the range of use of ASA among patients after acute coronary syndromes or $\mathrm{PCl}$ may change on the basis of the findings of the WOEST study, in which 573 subjects were randomized to a group with double anticoagulant therapy including clopidogrel (75 mg daily) or to a group with triple anticoagulant therapy based on the oral anticoagulant drug clopidogrel and acetylsalicylic acid at a dose of $80 \mathrm{mg} /$ day [22]. Bleeding occurred in $44.9 \%$ of subjects receiving triple therapy and in $19.5 \%$ of subjects treated with anticoagulant and clopidogrel. In addition to that, in the group of patients who were subjected to double therapy the outcome events occurred less often than in patients who received triple therapy: death $(2.6 \%$ vs. $6.4 \%, p=0.027)$, MI (3.3\% vs. $4.7 \%, p=0.382)$, stroke $(1.1 \%$ vs. $2.9 \%, p=0.128)$ and thrombosis in a stent $(1.5 \%$ vs. $3.2 \%, p=0.165)$.

Therefore, further experiments and study findings are necessary to clearly determine the safest and most effective dose of the new oral anticoagulants which could be used in combination with antiplatelet drugs.

\section{References}

1. Nieuwlaat R, Capucci A, Camm AJ, et al. Atrial fibrillation management: a prospective survey in ESC member countries: the Euro Heart Survey on Atrial Fibrillation. Eur Heart J 2005; 26: 2422-2234

2. Dagres N, Neewlat R, Vardas PE, et al. Gender-related differences in presentation, treatment, and outcome of patients with atrial fibrillation in Europe: a report from the Euro Heart Survey on Atrial Fibrillation. J Am Coll Cardiol 2007; 49: 572-577.

3. Camm AJ, Lip GY, De Caterina R, et al. 2012 focused update of the ESC Guidelines for the management of atrial fibrillation: an update of the 2010 ESC Guidelines for the management of atrial fibrillation. Eur Heart J 2012; 33: 2719-2747.

4. Fox KA, Steg PG, Eagle KA, et al. Decline in rates of death and heart failure in acute coronary syndromes, 1999-2006. JAMA 2007; 297: 1892-1900.

5. Hurlen M, Abdelnoor M, Smith P, et al. Warfarin, aspirin, or both after myocardial infarction. N Engl I Med 2002; 347: 969-974.

6. Zhao HJ, Zheng ZT, Wang ZH, et al. "Triple therapy" rather than "triple threat": a meta-analysis of the two antithrombotic regimens after stent implantation in patients receiving long-term oral anticoagulant treatment. Chest 2011; 139: 260-270.

7. Lip GY, Huber K, Andreotti F, et al. Management of antithrombotic therapy in atrial fibrillation patients presenting with acute coronary syndrome and/or undergoing percutaneous coronary intervention/stenting. Thromb Haemost 2010; 103: 13-28.

8. Wallentin L, Wilcox RG, Weaver WD, et al. Oral ximelagatran for secondary prophylaxis after myocardial infarction: the ESTEEM randomised controlled trial. Lancet 2003; 362: 789-797.

9. Oldgren J, Budaj A, Granger CB, et al. Dabigatran vs. placebo in patients with acute coronary syndromes on dual antiplatelet ther- apy: a randomized, double-blind, phase II trial. Eur Heart J 2011; 32: $2781-2789$.

10. Alexander JH, Becker RC, Bhatt DL, et al. Apixaban, an oral, direct, selective factor $\mathrm{Xa}$ inhibitor, in combination with antiplatelet therapy after acute coronary syndrome: results of the Apixaban for Prevention of Acute Ischemic and Safety Events (APPRAISE) trial. Circulation 2009; 119: 2877-2885.

11. Alexander JH, Lopes RD, James S, et al. Apixaban with antiplatelet therapy after acute coronary syndrome. N Engl J Med 2011; 365: 699-708.

12. Steg PG, Mehta SR, Jukema JW, et al. RUBY-1: a randomized, double-blind, placebo-controlled trial of the safety and tolerability of the novel oral factor Xa inhibitor darexaban (YM150) following acute coronary syndrome. Eur Heart I 2011; 32: 2541-2554.

13. Mega JL, Braunwald E, Mohanavelu S, et al. Rivaroxaban versus placebo in patients with acute coronary syndromes (ATLAS ACS TIMI 46): a randomised, double-blind, phase II trial. Lancet 2009; 374: 29-38.

14. Mega JL, Braunwald E, Wiviott SD, et al. Rivaroxaban in patients with a recent acute coronary syndrome. N Engl J Med 2012; 366: 9-19.

15. Oldgren J, Wallentin L, Alexander JH, et al. New oral anticoagulants in addition to single or dual antiplatelet therapy after an acute coronary syndrome: a systematic review and meta-analysis. Eur Heart J 2013; 34: 1670-1680.

16. Komócsi A, Vorobcsuk A, Kehl D, et al. Use of new-generation oral anticoagulant agents in patients receiving antiplatelet therapy after an acute coronary syndrome systematic review and meta-analysis of randomized controlled trials. Arch Intern Med 2012; 172: 1537-1545.

17. De Caterina R, Husted S, Wallentin L, et al. New oral anticoagulants in atrial fibrillation and acute coronary syndromes: ESC Working Group on Thrombosis-Task Force on Anticoagulants in Heart Disease position paper. J Am Coll Cardiol 2012; 59: 1413-1425.

18. Filipiak KJ. Świat po badaniu ATLAS ACS 2 TIMI 51: czy po ostrym zespole wieńcowym wystarczy już tylko podawanie dwóch leków przeciwpłytkowych [Polish]? Kardiol Pol 2012; 70: 437-438.

19. Heidbuchel H, Verhamme P, Alings $M$, et al. European Heart Rhythm Association Practical Guide on the use of new oral anticoagulants in patients with non-valvular atrial fibrillation. Europace 2013; 15: 625-651.

20. Steg PG, James SK, Atar D, et al. ESC Guidelines for the management of acute myocardial infarction in patients presenting with ST-segment elevation. Eur Heart J 2012; 33: 2569-2619.

21. Hamm CW, Bassand JP, Agewall S, et al. ESC Guidelines for the management of acute coronary syndromes in patients presenting without persistent ST-segment elevation: The Task Force for the management of acute coronary syndromes (ACS) in patients presenting without persistent ST-segment elevation of the European Society of Cardiology (ESC). Eur Heart J 2011; 32: 2999-3054.

22. Dewilde WJ, Oirbans T, Verheugt FW, et al.; WOEST study investigators. Use of clopidogrel with or without aspirin in patients taking oral anticoagulant therapy and undergoing percutaneous coronary intervention: an open-label, randomised, controlled trial. Lancet 2013; 381: 1107-1115. 